\title{
Construction of Quality Evaluation System of English Education in Colleges and Universities
}

\author{
Wei Geng \\ School of Foreign Languages, Inner Mongolia University of Science and Technology, Baotou, \\ 014010, China
}

Keywords: Colleges and Universities. English. Education Quality. Evaluation System

\begin{abstract}
Quality evaluation of English education is an important part of English education in higher education. Quality evaluation system of English education in colleges and universities should be comprehensive and objective and education quality evaluation should combine students' test scores and daily performance. Reasonable education quality evaluation system has become an important guarantee to improve college students' capability of learning English. This paper discusses the requirements of quality of education in the era of popularized higher education, analyzes the current outstanding problems of English education quality evaluation system in colleges and universities, and proposes a strategy to strengthen English education quality evaluation system in colleges and universities.
\end{abstract}

\section{Introduction}

Education quality in higher Education is the consistent level between quality development ability of college students and the curriculum, professions and target generation of talent cultivation. Education quality evaluation system, through the use of education evaluation theory and educational technology, determines whether the education process and results can meet the requirements of the quality. Scientific and standardized quality evaluation system of English education plays a very crucial role for enhancing the quality of English teaching. English is the most important public course which has the most school hours and it is also the largest energy-consuming course in colleges and universities. To promote the construction of education quality evaluation system for English courses in colleges and universities can better inspire college students to strengthen their interest in learning English and to develop their ability of learning English independently and the ability of the comprehensive application of the English language, while it can also improve English teachers' comprehensive ability which is very important in improving the quality of English education in colleges and universities.

\section{Requirements of Education Quality in the Era of Higher Education Popularization}

Since the higher education in our country has went into the period of popularization, not only the number of colleges and universities increased obviously but also the quality of colleges and universities changed dramatically, which led to the great changes in the value of education quality. Diversification is a distinctive feature of popularization of higher education and it is also an important premise of promoting the popularization of education. It is an inevitable requirement for higher education popularization to set diversified standard for education quality, the main manifestation of which is the diversification of connotation and value of education of different types and levels. Just observing from aspect of the educational value orientation, there are two types of standards, academic standard and social function standard, to judge the educational quality especially for the quality of talent training. There are two kinds of development tendencies for colleges and universities in the stage of popularization, elite education and popular education, which show the combination of educational academic orientation and social orientation. Emphasis on social function orientation is one of the greatest changes of standards of quality of popularized education. Higher education is very important for the development of economy and society. Academic standard is related to social 
function standard in popularized education and they can keep pace with each other as a whole but they have difference on the standards of quality on specific education of different types and levels. Diversification should be taken into consideration in the quality of education and we should try not to use a uniform measurement to gauge the quality of education.

\section{Existing Outstanding Problems in Current Quality Evaluation System of English Education in Colleges and Universities}

\section{Subject of evaluation is excessively single and lack of comprehensiveness.}

In the process of evaluation of English educational quality in colleges and universities, teachers always evaluate students, lacking students' evaluation of teachers and mutual evaluations among students, meanwhile the parents of students and people from all walks of life seldom take part into the educational evaluation. So the resources of evaluation information is single and limited, lacking the comprehension of higher education from all aspects, which makes the evaluation subjective and one-sided and leads to the inadequacy of effectiveness. What's worse, it can also result in that teachers always ignore students' subjective feelings, which has bad influence on the learning initiative and the construction of self-consciousness of students. Meanwhile, it weakens college students' confidence, affects their health physically and mentally, which would be not conducive for the personality development of students.

\section{Evaluation indicators are too vague and lack of pertinence.}

From the point of design of current indicators of evaluation of English education in colleges and universities, the designer tries his every effort to get more comprehensive results of evaluation of educational quality of teachers in colleges and universities, adding some indicators which cannot be evaluated correctly into the system. For example, some systems of evaluation indicators can reflect the new methods and new ideas in the development of English courses; they can also apply the theories to real-life situations to use teaching methods more reasonably. It is obviously difficult to get accurate evaluation to let the college students evaluate some contents which cannot be evaluated. In the evaluation process, we often emphasis too much on the commonalities and ignore the personality, only using immobilized and stylized indicators to measure teaching activities which should have been highly personalized and distinctive.

\section{Evaluation methods are too quantitative and lack of scientificalness.}

In the evaluation of the quality of education, there is often a situation which oversimplifies and quantifies the results of the evaluation. In order to rank student and elect the superior and the inferior, colleges and universities often neglect the combination of quality and quantity. In fact, teaching is very complex, some features cannot be precisely defined by some indicators of amount, such as education teaching attitude, English classroom atmosphere is good, better, middle or poor and so on. The boundaries between them and the standards are quite difficult to grasp which will certainly lead to the individual evaluators integrate emotional factors in the evaluation process, so that the quality of education would lose scientific nature which should have been there.

\section{Evaluation means are too simple and lack of authority.}

For the means of quality evaluation of English education in colleges and universities, some colleges and universities take the form of filing in a form or filling a card. Because it belongs to manual operation, it not only takes a lot of manpower and material resources, but also it is not easy to find enough templates. Besides, through artificial statistics processing, it is likely to let students to evaluate some relevant contents beyond their reach, so it is easy to cause relatively large errors. Therefore, the results of the evaluation will lack sufficient authority. 


\section{Strategy of Strengthening the Construction of Quality Evaluation System of English Education in Colleges and Universities}

\section{Determining the evaluation subject scientifically and reasonably.}

Evaluation subject and evaluation forms of quality evaluation system of English education in higher education should be diversified. It should not only involve the English teachers and students to combine the evaluation into the learning of college students throughout the entire process of education and teaching. In order to form a more open and relaxed atmosphere of the evaluation, students, classmates, teachers and parents should pay their attention on the evaluation. They should take part in the evaluation actively, so that the subjects of evaluation can be diversified. The students' evaluation, peer evaluation among students, teachers, peer evaluation among teachers and parents' evaluation should be combined. The first type is college students' self-evaluation. This evaluation allows college students to convert to evaluation participants from the evaluation objects more directly, so that they could truly appreciate the progress gotten bit by bit and their harvest, and in students' self-reflection and self-education they can realize the purpose of improving the learning attitudes and learning knowledge. The second type is peer evaluation among college students, which was conducted relatively less before. Cooperative learning among students in groups has been very common, and the evaluation also needs to rely on cooperation to be completed. Every college student, on the basis of self-assessment, should write a corresponding comment of the classroom for his companions to strengthen care and help between each other. The third type is peer evaluation among teachers. This means that the peer teachers, based on the lectures, review meetings and other relevant forms, evaluate the performance of English instructor in educational activities. This assessment is not only a useful supplement to the score evaluation of college students, but also can be more comprehensive and accurate. Because peer teachers are more capable than college students to make a comprehensive evaluation of the difficulty of English textbooks, the integrity of teaching content and whether the goal of classroom teaching is achieved. Meanwhile, teachers can put the education activities under a broader context, and make more practical recommendations to the teaching methods to the evaluated teachers. The fourth type is parents' evaluation. This assessment is also very important because parents understand students most. Colleges and universities should give the materials of the students' assessment, peer assessment among students and teachers' evaluation to parents and ask them to read the materials and then receive their feedback, which can make the education quality evaluation system more comprehensive.

\section{Determining reasonable evaluation indicators.}

Methods of quality evaluation system of English education in colleges and universities include not only summative evaluation, but also formative and diagnostic assessment. Only combining all the above evaluation methods can we make an effective evaluation of teaching and learning in higher education. Summative evaluation detects mainly development degree of college students' ability of integrated application of language, which is a major indicator reflecting the effectiveness and quality of education in higher education. Such a test just relied on the written test and it focused on pronunciation, grammar and vocabulary knowledge before, but it ignored the comprehensive ability of application languages of college students. In order to better examine the their practical ability of application the language, practical questions with context should be added into the test, objective questions should be decreased reasonably and subjective questions should be increased so that the thinking skills, presentation skills and communication skills of college students and other skills can be really tested, especially through years of efforts listening tests was intensified. Formative evaluation is very comprehensive and integrated, so many forms can be used. Except for the forms mentioned above, there are job evaluation, learning portfolios, interviews, and weekly diary and so on. In the English education, the most common evaluation is diagnostic evaluation of English courses. This assessment is flexible and diversified, which is generally implemented in class for either a long time or a short time. Some quizzes are implemented in order to the consolidation of knowledge in the classroom, while others are for the unit or periodic testing. Therefore, when implementing evaluation, all the three methods can be combined 


\section{Application of Scientific and Effective Evaluation Means}

Firstly, we should establish English learning files. Through the establishment of English Learning folder of students in colleges and universities, students' every effort in the classroom learning of English and any progress obtained can be reflected in a form of folder. College students have representative learning results and reflection report, by the means of setting up English learning files, college students can be urged to regularly check the completion condition of their job in more satisfied work selected by themselves. So they can introspect their own learning methods and achievements and develop their self-confidence of learning. Secondly, we should set up the network evaluation system. Currently, multimedia and networking teaching situation erect network platform for colleges and universities. College English teachers can use the platform to carry out real-time evaluation or time-lapse evaluation for the process of teaching. Using the network to do real-time evaluation, learners are unrestricted by time and space and they can implement real-time communication in different places on the English text, images and video and audio through modern communication methods. This quality evaluation system reflects the fast and flexible features of English teaching by network. It can also provide feedbacks for English learning of college students in time and carry out effective monitoring and manage the whole process of teaching to improve teaching efficiency and strengthen the controlling intensity of English teaching in colleges and universities. Time-lapse network evaluation is a new mean of evaluation, which allows students to find problems in a timely manner, thus form a creative view. Time-lapse evaluation is mainly a dynamic evaluation method, in this dynamic process, not only college students' intelligence develops, but also students' skills of language self-learning can be trained. Thirdly, we should establish a platform for the communication of teachers and students. University teachers and students can also apply e-mail, QQ and other social networking tools. English teachers can conduct a summary analysis on all kinds of information on the social tools mentioned above to find related issues in English teaching of network and to adjust teaching strategies timely to improve the effect of English education.

\section{Construction of Diversified Evaluation System}

Because of the introduction and learning of all kinds of theories, colleges and universities continuously carry out the attempts of English education quality evaluation. Compared with previous condition, college English education quality evaluation approaches focus more on the combination of self-evaluation and peer assessment, pay attention to the combination of summative evaluation and formative evaluation and the combination of qualitative evaluation and quantitative evaluation, so methods of quality evaluation system of English education in colleges and universities become more and more abundant. So a diversified view of quality evaluation of English education in colleges and universities and quality standards and a diversified English education quality evaluation system in colleges and universities are not only necessary to adapt to the popularization of education, but also are the requirements of reformation of English education in colleges and universities. In an era of popularized education, we should effectively change our ideas and we should have courage to implement reformation and innovation. We should also continue to improve the quality and the level of English education in colleges and universities to truly meet the new demands of society and economy for talent.

\section{Conclusion}

All in all, in order to carry out the quality evaluation of English education in colleges and universities, it is necessary to establish a scientific and standardized English education quality evaluation system, encourage English teachers to organize classroom teaching according to the law of higher education sufficiently and truly realize the concept of learner-centered education. Besides, we should put the emphasis on improving the quality of classroom education and guide the overall construction of all the aspects in teaching. What's more, we should get rid of the constraints of examination-oriented education comprehensively to a certain extent and vigorously promote the development of quality education. We should apply a variety of evaluation tools to improve the 
quality of English education and to promote the English teaching activities to achieve tangible results, simultaneously improving the quality of English teachers.

\section{Acknowledgments}

This paper is the interim inspecting result of foreign language study of Inner Mongolia Social Science Planning: learning from Canadian "immersion education model” to enhance the study of strategies for cultural soft power of foreign language in the colleges and universities in our region. Subject N.O.:2013B129

\section{References}

[1] Wu Dianlong: Specific Methods of Formative Evaluation of English Subject, Journal of Changchun Normal University, 2009(28).

[2] Wu Kerong, Nai Peng: Modern Education Technique and Quality Evaluation of English Education in Colleges and Universities, Journal of Dongguan University of Technology, 2010(12).

[3] Zhou Guobao: Diversification of Quality Evaluation System of English Education in Colleges and Universities, China Adult Education, 2012(3)

[4] Bai Jingyong: Research on Quality Evaluation System of English Education in Higher Vocational Education , Journal of Naning Junior Teachers College, 2012(4).

[5] Lu Changxing: Construction of Quality Evaluation System of English Education and Applicability Students Comprehensive Ability, Economic Research Guide, 2013(4)

[6] Zheng Wei: Improvement of Quality Monitoring and Evaluation System of English Education in Colleges and Universities, Theory Research, 2013(15). 